\title{
Removal of Pesticide (Oxamyl) from Water using Activated Carbons Developed from Apricot Stones
}

\author{
Th. El-Nabarawy ${ }^{1}$, S. A. Sayed ${ }^{1}$ Ahmed and A. M. youssef ${ }^{2, A}$ \\ ${ }^{1}$ National Research Centre, Dokki, Cairo, Egypt \\ ${ }^{2}$ Faculty of science, Mansoura University, Egypt \\ ^e-mail: amayosef@mans.edu.eg \\ (Received April 10, 2007; Accepted December 16, 2007)
}

\begin{abstract}
Four stream- activated carbons were prepared by carbonizing apricot stones at $600^{\circ} \mathrm{C}$ followed by gasification with steam at $950^{\circ} \mathrm{C}$ to burn-off's $=17,32,49$ and $65 \%$. The textural parameters of these activated carbons were determined from nitrogen adsorption results at $77 \mathrm{~K}$. The total pore volume and the mean pore radius increased with the increase of \% burn-off whereas the surface area increased with the increase of burn- off from 17 to 32 and further to $49 \%$. Further increase of burn-off to $65 \%$ was associated with a considerable decrease in surface area as a result of pronounced pore widening due to pore erosion. The surface $\mathrm{pH}$ values of the carbons investigated range between 7.1 and 8.2. The adsorption of oxamyl onto the activated carbon followed pseudo-second order kinetics and the equilibrium adsorption isotherms fitted Langmuir adsorption model. The adsorption of oxamyl proved to be of the physical type and took place in non-micropores. The amount of oxamyl adsorbed expressed as $\mathrm{q}_{\mathrm{m}}$ depends to a large extent to the surface area located in non-micropores $\mathrm{S}_{\mathrm{n}}{ }_{\mathrm{n}}$, where a straight line relationship passing through the origin was obtained.
\end{abstract}

Keywords : Pesticide, Activated Carbons, Apricot Stones

\section{Introduction}

Environmental pollution has become a major issue in agriculture during the past several years because the increased use of pesticides has led to a greater emphasis on serious environmental contamination. The frequent detection of pesticides in surface and ground water $[1,6]$ has increased interest in finding the proper technique for the removal of pesticides from water either completely or by minimizing their concentrations down to the safe level.

The technique of adsorption has been found to be a useful means for controlling the extent of water pollution due to dyes, metallic species, organic pollutants and pesticides [7, 12]. The major advantages of adsorption system for water pollution control are less investment in terms of initial cost and land [13, 14], simple design [15] and easy operation [16, 17]. It also has the advantage of superior removal of organic waste contaminants compared to the biological treatment processes [18]. Among adsorbents used for water pollution control, adsorption by activated carbons (ACs) proved to be the most efficient. ACs relate to a group of materials with highly developed surface area and porosity and have a large adsorption capacity for various adsorptive both from solutions and from gaseous phase [19, 20]. ACs also find a use in catalysis where they may be used as catalysts [21] or as catalyst supports [22]. The treatment of surface and wastewater are new important fields in which ACs are very effective [23].

ACs can be produced from any carbonaceous material precursor, both naturally occurring and synthetic. Common examples of commercial feedstocks are materials of botanical origin (e.g. wood, coconut shell, nut kernels, rice straw, fruit stones, corn cobs, cotton stalks and others) and degraded or coalified materials. ACs are obtained by following one of two procedures: chemical activation or physical activation. In chemical activation, the precursor in a divided form is mixed with an activating agent such as zinc chloride, phosphoric acid or potassium salts and the mixture is then carbonized in absence of air or in an inert atmosphere not exceeding $1000 \mathrm{~K}$ [24]. Physical activation is more frequently used and is performed by gasifying non- activated carbon with a stream of oxidizing gas to a certain degree of burn- off [25].

Ethanimidothioic acid 2- (dimethylamino)-N-((( methylamino) carbonyl) oxy)-2-oxo-methyl ester [(CH3)2 N-C$\mathrm{C}=\mathrm{N}-\mathrm{O}-\mathrm{C}-\mathrm{NHCH} 3]$ is a broad leaf, non-volatile, insecticide, menatocide which has been widely used in agriculture for a long time for the control of nematode problems which have been developed in crops production. The frequent detection of pesticides including oxamyl in ground and surface water has increased experimental studies on pesticide adsorption by soils. However, the data on pesticide adsorption by ACs 
are still limited and further investigations are still required in this concern.

The major purposes of the present work was to: (i)determine the kinetics of adsorption of oxamyl from aqueous solution using steam- activated carbons with various percentages of burn-off. (ii)- determine the adsorption capacities of ACs for this pollutant and the change of the adsorption capacity in the temperature range $298-318 \mathrm{~K}$, i.e at temperatures around the ambient temperature in many countries and meanwhile to determine the thermodynamic parameters of oxamyl adsorption by ACs. (iii) relate the oxamyl adsorption capacity to some of the textural parameters of ACs investigated.

\section{Experimental}

\subsection{Materials}

Dry clean apricot stones were crushed to a particle size of 0.6-1.5 $\mathrm{mm}$ in diameter before carbonization in absence of air at $600^{\circ} \mathrm{C}$. The rate of heating was $10 \mathrm{~K} / \mathrm{min}$ and the sample was soaked at $600^{\circ} \mathrm{C}$ for $2 \mathrm{~h}$. The textural parameters of " $\mathrm{C}$ " were determined in a previous work to be the suface area $=288 \mathrm{~m}^{2} / \mathrm{g}$; the total pore volume $0.132 \mathrm{~mL} / \mathrm{g}$ and the mean pore radius $=0.92 \mathrm{~nm}$. The carbonization product " $\mathrm{C}$ " was used for the preparation of steam-activated carbons "CS". Portions of "C" were gasified with a mixture of nitrogen and steam at $950^{\circ} \mathrm{C}$ in a tubular muffle furnace to burn-off's $=17,32,49$ and $65 \%$ to give ACs designated CS17, CS32, CS49 and CS65, respectively. Details of steamactivation are given elsewhere [25].

Oxamyl, a product of Du Pont (Wilonigton, Dela.) was used as received. Other reagents including $\mathrm{CuSO}_{4}, 5 \mathrm{H}_{2} \mathrm{O}$, $\mathrm{CH}_{3} \mathrm{COONH}_{4}, \mathrm{NH}_{4} \mathrm{OH}, \mathrm{NaOH}, \mathrm{CS}_{2}, \mathrm{KOH}$ and $\mathrm{CH}_{3} \mathrm{COOH}$, were $\mathrm{BDH}$ analytical grade.

\subsection{Techniques}

The textural properties of the activated carbons were determined from nitrogen adsorption at $77 \mathrm{~K}$ using conventional volumetric apparatus. Prior to any adsorption measurement, the AC sample was degassed at $200^{\circ} \mathrm{C}$ for $6 \mathrm{~h}$ under a reduced pressure of $10^{-5}$ Torr. The surface $\mathrm{pH}$ of the carbons and also of the aqueous solution of oxamyl were measured using digital $\mathrm{pH}$ meter (pope model No 1501). The kinetic adsorption of oxamyl by ACs at $298 \mathrm{~K}$ were undertaken by determining the amounts of oxamyl adsorbed per one gram adsorbent at different intervals of time up to $6 \mathrm{~h}$. The equilibrium adsorption was undertaken using the batch shaking technique. Suitable aliquots (1-10 mL) of an aqueous solution of oxamyl were introduced into different $50 \mathrm{~mL}$ glass conical flasks which were then stoppered. Each experiment was conducted in duplicate and each isotherm

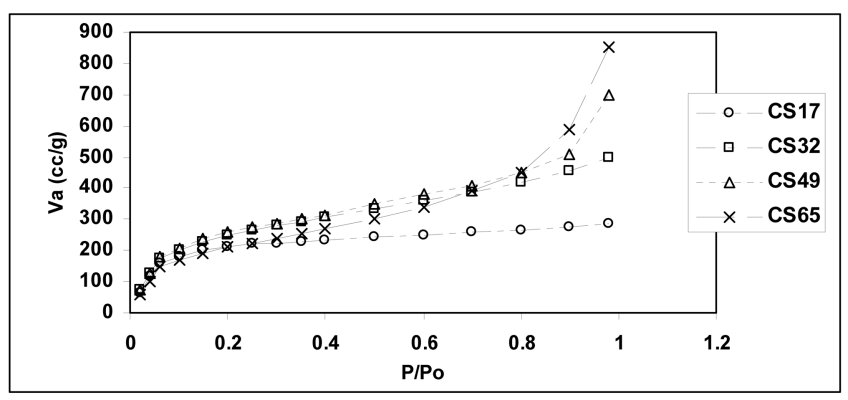

Fig. 1. Adsorption isotherms of $\mathrm{N}_{2}$ at $77 \mathrm{~K}$ onto ACs investigated.

determination involved 21 flasks for each of 10 oxamyl doses plus one as a blank containing the carbon sample with no oxamyl. The suspensions were shaken in an incubator at 298, 305, 313 and $318 \mathrm{~K}$. Each suspension was centrifuged for $10 \mathrm{~min}$ at $5000 \mathrm{rpm}$, the supernatant liquid was collected and estimated spectrophotometrically. Details of oxamyl determination are reported elsewhere [26].

\section{Results and discussion}

\subsection{Textural properties}

The adsorption of nitrogen on ACs investigated at $77 \mathrm{~K}$ proved to be rapid with the equilibrium attained within 30 min. The nitrogen adsorption isotherms are shown in Fig.1. The shape of the isotherm changed with the change of the degree of gasification of the carbon with steam, i.e. with the percentage burn-off. Thus, the nitrogen adsorption isotherm of CS17 was typical type I according to the BDDT classification [27]. CS65 exhibited, on the other hand, typical type II in the same classification. CS32 and CS49 exhibited nitrogen adsorption isotherms showing both the characteristics of type I and type II. The nitrogen adsorption isotherms were analyzed using the BET equation [28], which allowed the determination of the surface area $\mathrm{S}_{\mathrm{BET}}\left(\mathrm{m}^{2} / \mathrm{g}\right)$, adopting the value of $0.162 \mathrm{~nm}^{2}$ for the cross-sectional area of nitrogen at $77 \mathrm{~K}$. The total pore volume of each carbon, $\mathrm{V}_{\mathrm{T}}(\mathrm{mL} / \mathrm{g})$ was read from the amount of nitrogen adsorbed very close to saturation i.e. at $\mathrm{P} / \mathrm{P}_{\mathrm{o}} \simeq 0.98$ as shown on the isotherm. Another important textural parameter, namely the mean pore radius $r_{m}(n m)$ could be obtained from the relationship.

$$
\overline{\mathrm{r}}(\mathrm{nm})=\frac{2 \mathrm{~V}_{\mathrm{T}}(\mathrm{mL} / \mathrm{g})}{\mathrm{S}_{\mathrm{BET}}\left(\mathrm{m}^{2} / \mathrm{g}\right)}
$$

The values of $\mathrm{S}_{\mathrm{BET}}, \mathrm{V}_{\mathrm{T}}$ and $\mathrm{r}_{\mathrm{m}}$ are listed respectively in columns 2, 3 and 4 of Table 1. Another independent method, namely, the $\alpha$-method [29] was also used to analyze the nitrogen adsorption isotherms. The $\alpha$-plots of nitrogen adsorption are depicted in Fig. 2 . The $\alpha$-method allowed also 
Table 1. Textural properties of the activated carbons

\begin{tabular}{ccccccccc}
\hline Carbon & $\mathrm{S}_{\mathrm{BET}} \mathrm{m}^{2} / \mathrm{g}$ & $\mathrm{V}_{\mathrm{T}} \mathrm{mL} / \mathrm{g}$ & $\mathrm{r}_{\mathrm{m}} \mathrm{nm}$ & ${ }_{\mathrm{s}} \mathrm{m}^{2} / \mathrm{g}$ & $\mathrm{S}^{\alpha}{ }_{\mathrm{n}} \mathrm{m}^{2} / \mathrm{g}$ & $\mathrm{S}^{\alpha}{ }_{\mathrm{m}} \mathrm{m}^{2} / \mathrm{g}$ & $\mathrm{V}^{\alpha}{ }_{\mathrm{n}} \mathrm{mL} / \mathrm{g}$ & $\mathrm{V}^{\alpha}{ }_{\mathrm{m}} \mathrm{mL} / \mathrm{g}$ \\
\hline $\mathrm{CS} 17$ & 725 & 0.448 & 1.24 & 750 & 210 & 540 & 0.138 & 0.310 \\
$\mathrm{CS} 32$ & 949 & 0.769 & 1.63 & 940 & 584 & 356 & 0.610 & 0.159 \\
$\mathrm{CS} 49$ & 970 & 1.178 & 2.43 & 950 & 672 & 278 & 1.038 & 0.140 \\
$\mathrm{CS} 65$ & 754 & 1.318 & 3.49 & 736 & 656 & 80 & 1.287 & 0.031 \\
\hline
\end{tabular}

the determination of the surface area $\alpha_{\mathrm{s}}\left(\mathrm{m}^{2} / \mathrm{g}\right)$, the surface areas located in micropores $\left(\mathrm{S}_{\mathrm{m}}^{\alpha}\right)$ and those located in nonmicrospores $\left(\mathrm{S}^{\alpha}{ }_{\mathrm{n}}\right)$. Another advantage of the a- method is the possibility of estimation of the micropore volume of the adsorbent $\mathrm{V}^{\alpha}{ }_{\mathrm{m}}$ and the non-micropore volume $\mathrm{V}^{\alpha}{ }_{\mathrm{n}}$. The standard data of nitrogen adsorption at $77 \mathrm{~K}$ by a nonporous carbon [30] were used in the analysis of the present nitrogen adsorption isotherms. $\alpha_{\mathrm{s}}, \mathrm{S}^{\alpha}{ }_{\mathrm{n}}, \mathrm{S}^{\alpha}{ }_{\mathrm{m}}, \mathrm{V}^{\alpha}{ }_{\mathrm{n}}$ and $\mathrm{V}^{\alpha}{ }_{\mathrm{m}}$ are listed in column 5, 6, 7, 8 and 9 of Table 1, respectively.

Inspection of Table 1 reveals that: (i) the surface areas of ACs as determined by the application of the $\alpha$-method $\left(\alpha_{\mathrm{s}}\right)$ are comparable to those determined from the BET method $\mathrm{S}_{\mathrm{BET}}$. (ii) The total pore volume and the mean pore radius increased with the increase of $\%$ bum- off. The surface area, on the other hand, considerably increased with the increase of $\%$ burn-off from 17 to $32 \%$. However, further increase of the $\%$ burn-off from 32 to $49 \%$ was associated with a slight increase in the surface area, i.e. with about $4 \%$ only. Moreover, further rise of burn-off to $65 \%$ resulted in a noticeable decrease in the surface area, i.e with approximately $29 \%$. (iii) The changes in the textural properties with the change in the percentage of burn-off probably indicated that at low burn-off, the activation with steam is associated with creation of new micropore, and slight widening to the existing ones. Steam-activation to higher percentages of burn-off, i.e. between 30 and $50 \%$ is associated with pore widening more than creation of micropores. Further increase of burn-off is probably associated with intensive errosion of the pores which may lead to a decrease in the surface area.

\subsection{Effect of $\mathrm{pH}$}

Among the factors determining the adsorption of an adsorptive from its aqueous solution, the $\mathrm{pH}$ and equilibrium time are the most important. Preliminary experiments have been carried out to determine the proper $\mathrm{pH}$ which leads to maximum oxamyl sorption. Evidently, when all other adsorption condition are same except solution $\mathrm{pH}$, maximum oxamyl sorption took place from solutions of $\mathrm{pH}=6.8$. This was true for all the carbons investigated in this work. Adsorption kinetics and adsorption isotherms of oxamyl were undertaken at $\mathrm{pH}=6.8$.

\subsection{Adsorption kinetics}

The rate of oxamyl adsorption by the activated carbons at
$298 \mathrm{~K}$ is presented in Fig. 3. It is apparent from the kinetic curves obtained that the equilibrium time was more or less the same which may be ascribed for the similarity of the sorbents, all are prepared from the same precursor and were activated by following the same technique. The attainment of equilibrium was relatively fast being within approximately the first hour of adsorption. The data depicted also show that the rate of oxamyl adsorption was very rapid initially, decreasing markedly between 10 and $60 \mathrm{~min}$, and
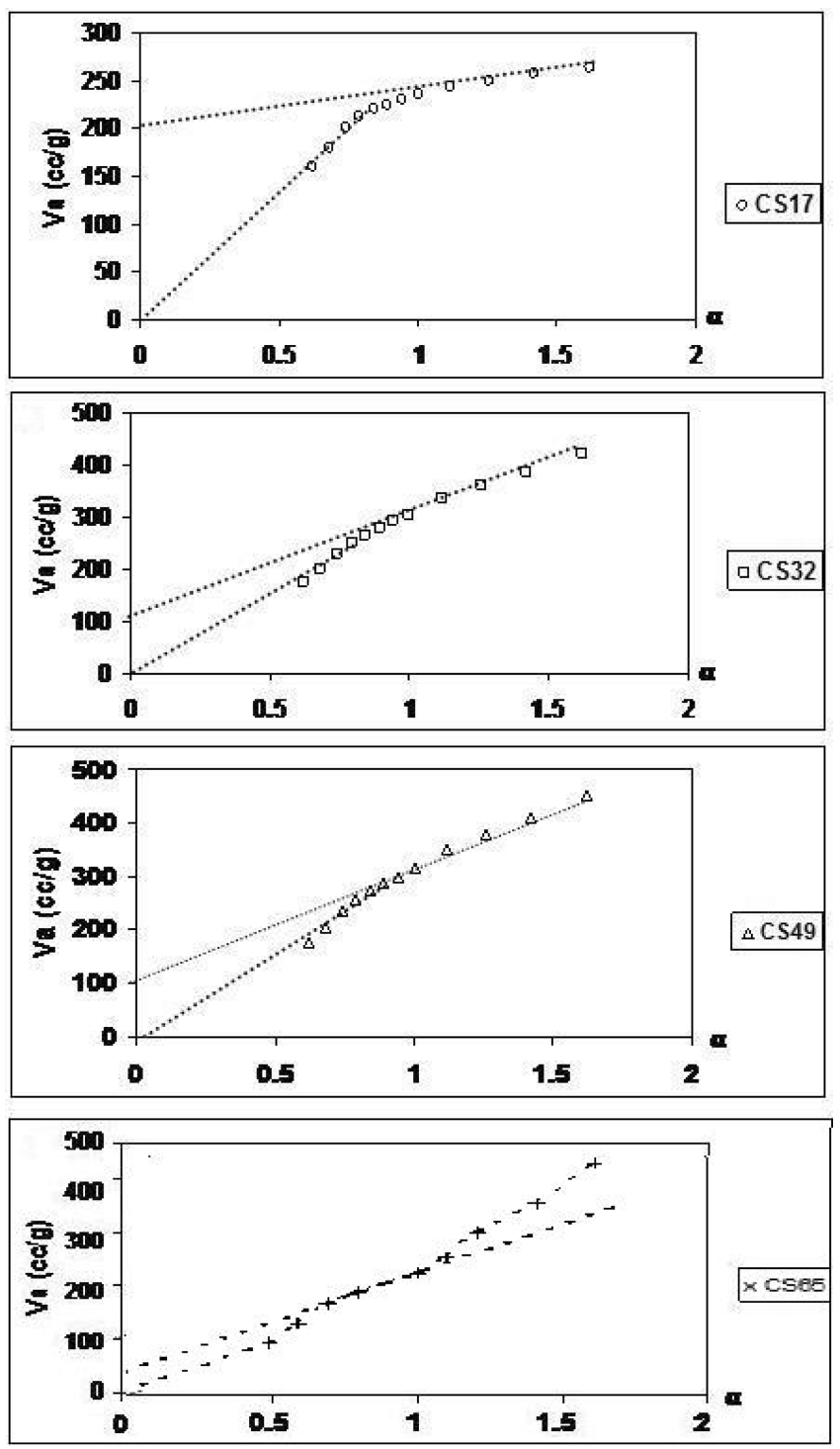

Fig. 2. Plots of $\mathrm{N}_{2}$ adsorption at $77 \mathrm{~K}$ onto ACs investigated. 
Table 2. Kinetic parameters of the adsorption of oxamyl at $298 \mathrm{~K}$ onto the activated carbons

\begin{tabular}{ccccccccc}
\hline Carbon & $\mathrm{K}_{1}\left(\mathrm{~min}^{-1}\right)$ & $\mathrm{q}_{\max } \mathrm{mg} / \mathrm{g}$ & $\mathrm{R}^{2}{ }_{1}$ & $\mathrm{~K}_{2} \times 10^{3} \mathrm{~g} /(\mathrm{mg} \min )$ & $\mathrm{q}_{\max } \mathrm{mg} / \mathrm{g}$ & $\mathrm{R}_{2}{ }_{2}$ & $\left.\mathrm{~K}_{\mathrm{p}} \mathrm{mg}(\mathrm{g} \mathrm{min})^{0.5}\right)^{2}$ & $\mathrm{R}_{\mathrm{p}}^{2}$ \\
\hline CS 17 & 32.6 & 4.17 & 0.9989 & 5.9 & 4.67 & 0.9907 & 0.39 & 0.9995 \\
CS 32 & 36.2 & 13.90 & 0.9993 & 2.3 & 13.33 & 0.9899 & 1.05 & 0.9990 \\
CS 49 & 26.4 & 14.97 & 0.9197 & 2.5 & 14.17 & 0.9903 & 1.18 & 0.9992 \\
CS 65 & 29.9 & 14.70 & 0.9197 & 2.6 & 13.50 & 0.9903 & 1.25 & 0.9971 \\
\hline
\end{tabular}

thereafter gradually approaching equilibrium.

Three kinetic models, i.e. the pseudo- first-order equation [31] [equation (1)], the pseudo-second-order equation [32] [equation (2)] and as intraparticle diffusion equation [33] [equation (3)], were considered to interpret the experimental data.

$$
\begin{aligned}
& \frac{1}{\mathrm{q}_{\mathrm{t}}}=\left[\frac{\mathrm{K}_{1}}{\mathrm{q}_{\max }}\right]\left[\frac{1}{\mathrm{t}}\right]+\frac{1}{\mathrm{q}_{\max }} \\
& \frac{\mathrm{t}}{\mathrm{q}_{\mathrm{t}}}=\frac{1}{\mathrm{~K}_{2} \mathrm{q}_{\max }^{2}}+\frac{1}{\mathrm{q}_{\max }} \mathrm{t} \\
& \mathrm{q}_{\mathrm{t}}=\mathrm{k}_{\mathrm{p}} \mathrm{t}^{0.5}
\end{aligned}
$$

where $q_{t}$ is the amount of oxamyl adsorbed $(\mathrm{mg} / \mathrm{g})$ at various times $\mathrm{t}(\mathrm{min}), \mathrm{q}_{\max }$ is the maximum adsorption capacity $(\mathrm{mg} /$ $\mathrm{g}), \mathrm{K}_{1}\left(\mathrm{~min}^{-1}\right)$ is the rate constant of the pseudo-first-order model for the adsorption process, $\mathrm{K}_{2}$ [g/ (mg min)] is the rate constant of the pseudo-second-order model for the adsorption process and $\mathrm{K}_{\mathrm{p}}$ is the intraparticle diffusion rate constant. All three models, adequately described the adsorption kinetics. Figure 4 demonstrates the application of

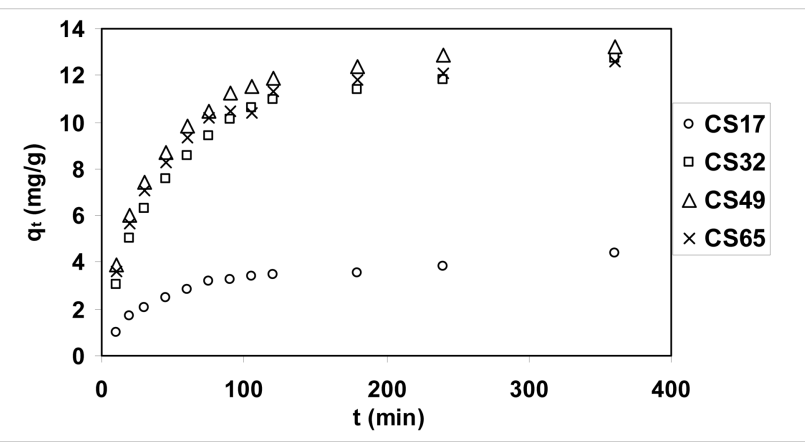

Fig. 3. Kinetic isotherms of oxamyl adsorption at $298 \mathrm{~K}$.

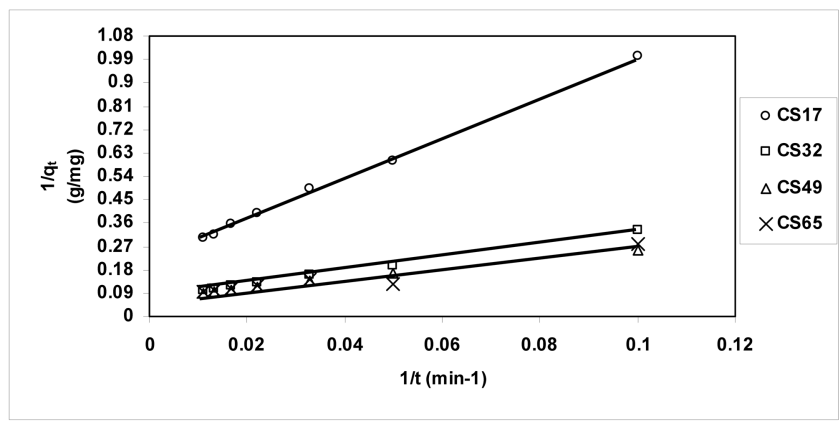

Fig. 4. Application of pseudo-first order rate equation to oxamyl adsorption data at $77 \mathrm{~K}$. the pseudo-first-order model to the adsorption data of oxamyl at $298 \mathrm{~K}$. The linear plots obtained allowed the determination of $\mathrm{K}_{1}$ for each oxamyl- carbon system and the correlation coefficient $\mathrm{R}^{2}$ determining the validity of the pseudo-first-order model. The values thus obtained are listed in Table 2.

In the present studies linear plots were obtained for oxamyl adsorption results onto the ACs when pseudo-firstorder model was applied (Fig. 4). However the experimental values of $\mathrm{q}_{\max }$ were not equal to the calculated values. Also, the values of correlation coefficients of oxamyl adsorption onto CS49 and CS65 as obtained by the application of pseudo-first-order model are low, i.e., 0.9197 (Table 2). This may indicate that adsorption of oxamyl on the ACs investigated did not proceed via pseudo-first-order reaction. Very satisfactory linear plots were obtained upon application of pseudo-second-order-rate equation (Fig. 5). The experimental $\mathrm{q}_{\max }$ values were in good agreement with the corresponding calculated values and the $\mathrm{R}^{2}$ were all approaching unity (Table 2). This favors the assumption that the adsorption of oxamyl on the ACs investigated proceeded via pseudo-second-order kinetics.

Intraparticle diffusion may be the rate- controlling step. If this does occur, then the plots of $\mathrm{q}_{t}$ versus $\mathrm{t}^{0.5}$ should be linear and if it passes through the origin then intraparticle diffusion will be the sole rate-limiting process [34]. In this study, it is shown in Fig. 6 that the plot of $\mathrm{q}_{\mathrm{t}}$ versus $\mathrm{t}^{0.5}$ exhibited an initial linear portions followed by downward deviation which occurred after $60 \mathrm{~min}$. The linear portions of the plots are probably attributed to the intraparticle diffusion, the initial downward deviation of the plots seems to be due to boundary layer adsorption whereas the plateau corresponds to the equilibrium. Although the linear plots passed through the origin, downward deviation existed in each plot

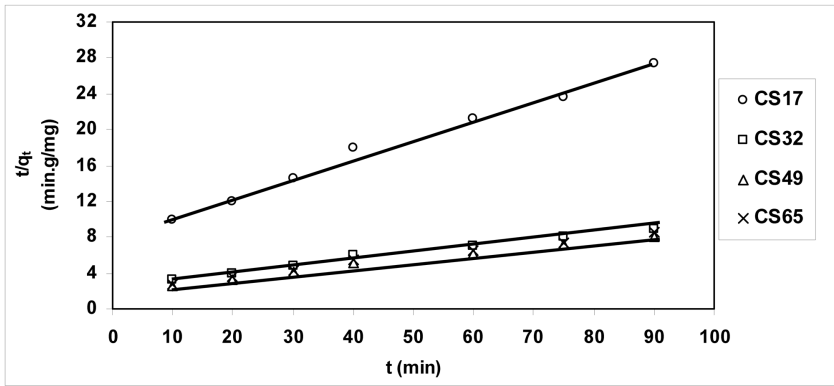

Fig. 5. Application of pseudo-second order rate equation to oxamyl adsorption data at $77 \mathrm{~K}$. 
Table 3. Langmuir constants of oxamyl adsorption onto the activated carbons

\begin{tabular}{|c|c|c|c|c|c|c|c|c|}
\hline \multirow{4}{*}{ Carbon } & \multicolumn{8}{|c|}{ Adsorption temperature (K) } \\
\hline & \multicolumn{2}{|c|}{298} & \multicolumn{2}{|c|}{305} & \multicolumn{2}{|c|}{313} & \multicolumn{2}{|c|}{318} \\
\hline & $\mathrm{q}_{\mathrm{m}}$ & $\mathrm{b}$ & $\mathrm{q}_{\mathrm{m}}$ & $\mathrm{b}$ & $\mathrm{q}_{\mathrm{m}}$ & $\mathrm{b}$ & $\mathrm{q}_{\mathrm{m}}$ & $\mathrm{b}$ \\
\hline & $\mathrm{mg} / \mathrm{g}$ & $\mathrm{L} / \mathrm{g}$ & $\mathrm{mg} / \mathrm{g}$ & $\mathrm{L} / \mathrm{g}$ & $\mathrm{mg} / \mathrm{g}$ & $\mathrm{L} / \mathrm{g}$ & $\mathrm{mg} / \mathrm{g}$ & $\mathrm{L} / \mathrm{g}$ \\
\hline CS 17 & 5.9 & 1.01 & 5.5 & 1.05 & 5.0 & 1.11 & 4.4 & 1.16 \\
\hline CS 32 & 15.9 & 1.01 & 14.5 & 1.03 & 13.2 & 1.05 & 12.1 & 1.08 \\
\hline CS 49 & 16.7 & 1.41 & 15.0 & 1.47 & 13.8 & 1.50 & 13.0 & 1.53 \\
\hline CS 65 & 15.2 & 1.01 & 14.0 & 1.12 & 12.9 & 1.28 & 12.1 & 1.45 \\
\hline
\end{tabular}

Table 4. The thermodynamic parameters of oxamyl adsorption by the activated carbons

\begin{tabular}{|c|c|c|c|c|c|c|c|c|c|}
\hline \multirow{4}{*}{ Carbon } & \multicolumn{9}{|c|}{ Adsorption temperature (K) } \\
\hline & \multicolumn{2}{|c|}{298} & \multicolumn{2}{|c|}{305} & \multicolumn{2}{|c|}{313} & \multicolumn{3}{|c|}{318} \\
\hline & $-\Delta \mathrm{G}^{0}$ & $-\Delta \mathrm{S}^{0}$ & $-\Delta G^{0}$ & $-\Delta \mathrm{S}^{0}$ & $-\Delta \mathrm{G}^{\mathrm{o}}$ & $-\Delta \mathrm{S}^{\mathrm{o}}$ & $-\Delta \mathrm{G}^{0}$ & $-\Delta \mathrm{S}^{0}$ & $-\Delta \mathrm{H}^{\circ}$ \\
\hline & $\mathrm{KJ} \mathrm{mol}^{-1}$ & $\mathrm{~J} \mathrm{~mol}^{-1} \mathrm{~K}^{-1}$ & $\mathrm{KJ} \mathrm{mol}^{-1}$ & $\mathrm{~J} \mathrm{~mol}^{-1} \mathrm{~K}^{-1}$ & $\mathrm{KJ} \mathrm{mol}^{-1}$ & $\mathrm{~J} \mathrm{~mol}^{-1} \mathrm{~K}^{-1}$ & $\mathrm{KJ} \mathrm{mol}^{-1}$ & $\mathrm{~J} \mathrm{~mol}^{-1} \mathrm{~K}^{-1}$ & $\mathrm{KJ} \mathrm{mol}^{-1}$ \\
\hline CS 17 & 0.085 & 49.0 & 0.127 & 48 & 0.270 & 40 & 0.391 & 45 & 14.7 \\
\hline CS 32 & 0.025 & 10.0 & 0.076 & 10 & 0.130 & 9 & 0.211 & 9 & 3.05 \\
\hline CS 49 & 0.85 & 8.0 & 0.98 & 7 & 1.05 & 7 & 1.12 & 6.6 & 3.23 \\
\hline CS 65 & 0.025 & 43 & 0.29 & 41 & 0.65 & 39 & 0.98 & 31 & 12.75 \\
\hline
\end{tabular}

which stands for boundary layer adsorption. This particular type of adsorption seems to be too small to control the adsorption process. The correlation coefficients for intraparticle diffusion model $\left(\mathrm{R}_{\mathrm{p}}^{2}\right)$ were $0.9995,0.9990,0.9992$ and 0.9971 for CS17, CS32, CS49 and CS65, respectively. These values indicate that the adsorption of the oxamyl onto activated carbons investigated may be followed by intra-

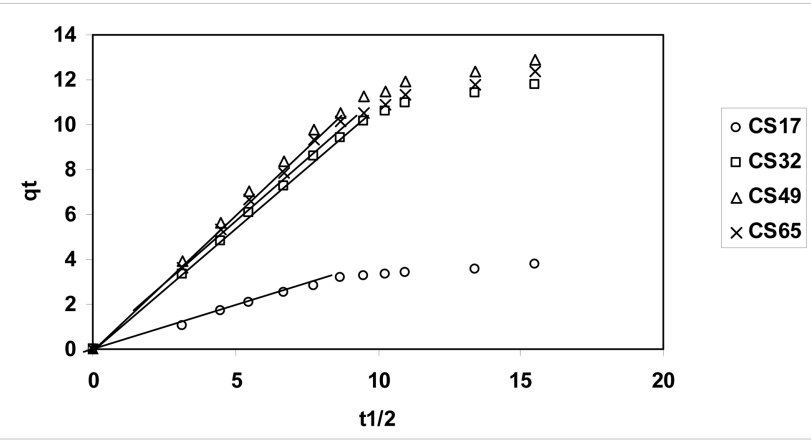

Fig. 6. Intraparticle diffussion plots for the adsorption of oxamyl at $298 \mathrm{~K}$ onto the activated carbon.

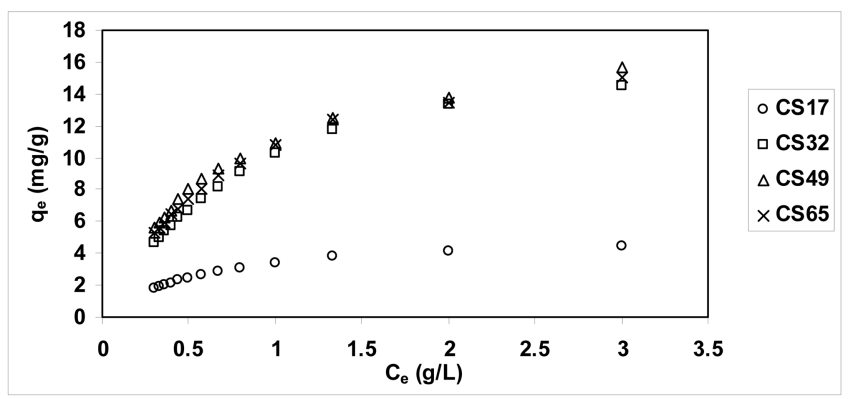

Fig. 7. Adsorption isotherms of oxamyl at $298 \mathrm{~K}$ onto ACs. particle diffusion up to $60 \mathrm{~min}$.

\subsection{Adsorption equilibrium}

The adsorption isotherm is important for describing the interaction of the solute with the sorbent which is critical in optimizing the use of the latter. In addition, the adsorption of solvated charged species and oriented dipoles existing at the activated carbon-electrolyte interface may be predicted by the adsorption behavior at different concentrations.

Figure 7, shows the oxamyl adsorption isotherms onto ACs investigated undertaken at $298 \mathrm{~K}$. The isotherms are typical type L according to Giles classification [35]. The adsorption data of oxamyl adsorption onto the ACs at 298, 305,313 and $318 \mathrm{~K}$ were analyzed using the widely used Langmuir equation [36]. The linear form of this equation may be represented as follows:

$$
\frac{1}{\mathrm{q}_{\mathrm{e}}}=\left(\frac{1}{\mathrm{~b} \cdot \mathrm{q}_{\mathrm{m}}}\right) \frac{1}{\mathrm{C}_{\mathrm{e}}}+\frac{1}{\mathrm{q}_{\mathrm{m}}}
$$

Where $\mathrm{q}_{\mathrm{e}}$ is the amount adsorbed $(\mathrm{mg} / \mathrm{g})$ at an equilibrium concentration $\mathrm{C}_{\mathrm{e}}(\mathrm{g} / \mathrm{L}), \mathrm{q}_{\mathrm{m}}(\mathrm{mg} / \mathrm{g})$ is the amount adsorbed corresponding to a complete monolayer coverage and $\mathrm{b}(\mathrm{L} / \mathrm{g})$ is known as Langmuir constant which can be used to determine the free energy change of the adsorption process using the relationship.

$$
\operatorname{Ln} \frac{1}{\mathrm{~b}}=\frac{\Delta \mathrm{G}^{\mathrm{o}}}{\mathrm{RT}} \text { or } \Delta \mathrm{G}=-\mathrm{RTInb}
$$

When the adsorption was carried out at different temperatures the enthalpy change $\mathrm{DH}$ could be calculated by plotting $\ln b$ versus $1 / T$ with the slope of this linear plot determining $\Delta \mathrm{H}$. Consequently the entropy change $\Delta \mathrm{S}^{\mathrm{o}}$ could 

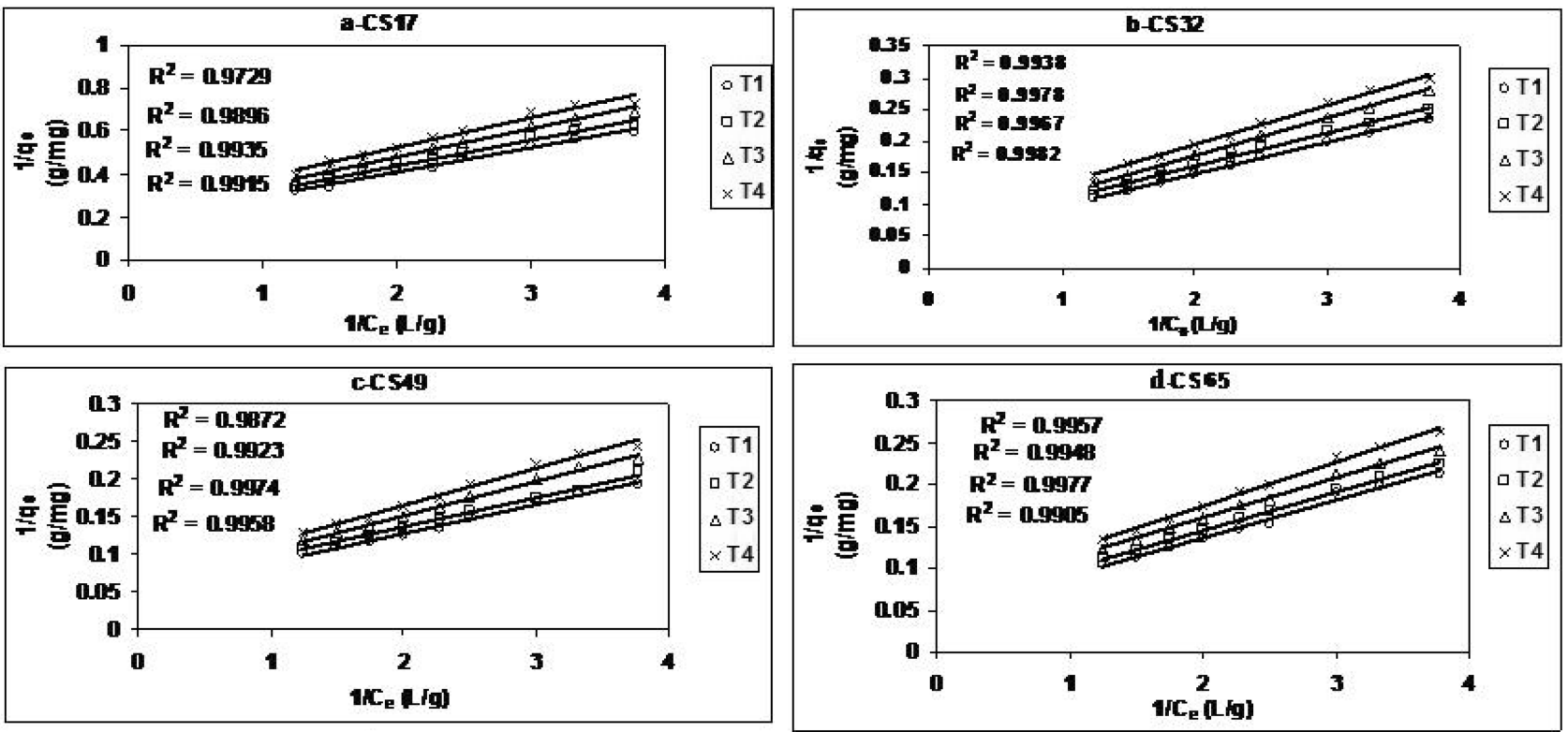

Fig. 8. Linear Langmoir plots of axamyl adsorption onto ACs at different Temperatures $(\mathrm{T} 1=298, \mathrm{~T} 2=305$, $\mathrm{T} 3=313$, $\mathrm{T} 4=318 \mathrm{~K})$.
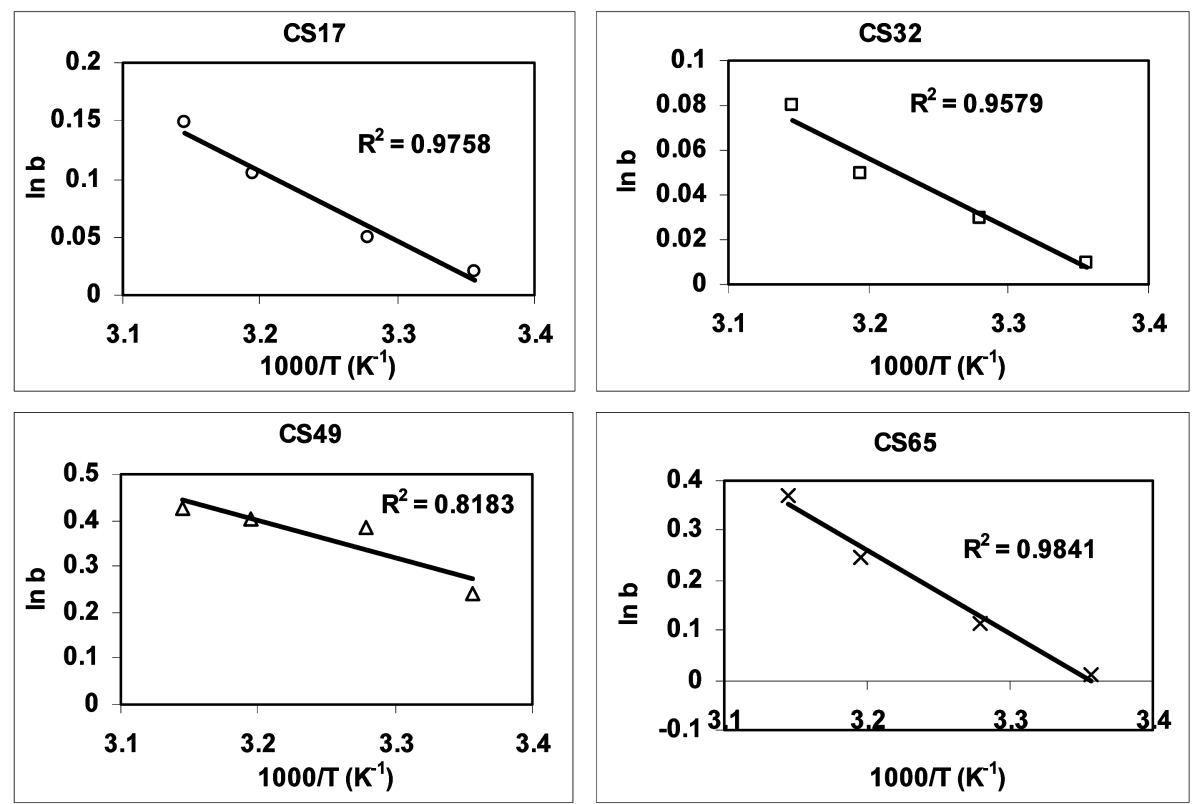

Fig. 9. $\ln \mathrm{b}$ versus $1000 / \mathrm{T}\left(\mathrm{K}^{-1}\right)$ for the investigated ACs.

be calculated from the relationship.

$$
\Delta S^{0}=\frac{\Delta H^{o}-\Delta G^{0}}{T}
$$

The linear Langmuir plots of oxamyl adsorption at 298, 305,313 and $318 \mathrm{~K}$ are shown in Fig. 8. Excellent linear plots are shown with considerably high values of correlation coefficient $\mathrm{R}^{2}$. Evidently, the monolayer capacities of samples CS32, CS49 and CS65 are comparable whereas that of CS17 is by far lower. This may be attributed to the different textural properties of the latter. This point will be discussed shortly.

The values of $\ln b$ versus $1 / \mathrm{T}$ are presented in Fig. 9. Satisfactory, straight line is shown. The values of $\mathrm{DH}^{\circ}$ were calculated and are listed in Table 4. Included also in this table are the values of $\Delta \mathrm{G}^{\circ}$ and $\Delta \mathrm{S}^{\circ}$.

Table 4 reveals that: although the values of $\Delta \mathrm{G}^{\circ}$ are relatively small, but they are all negative indicating that the adsorption of oxamyl by the ACs investigated in the temperature range $298-318 \mathrm{~K}$, is thermodynamically feasible. The negative values of $\mathrm{DH}^{\circ}$ indicate that the present adsorption process is a spontaneous process and the values 


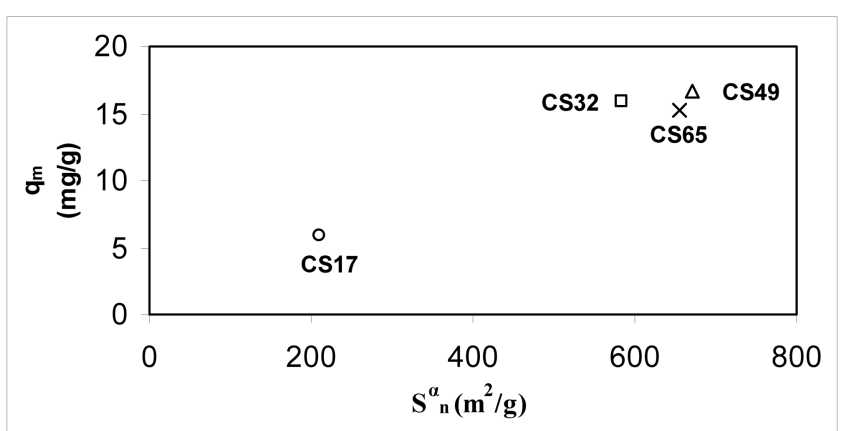

Fig. 10. qm at $298 \mathrm{~K}$ versus $\mathrm{S}_{\mathrm{n}}^{\alpha}$ for the investigated ACs.

of $\Delta \mathrm{H}$ refer to a physical adsorption process. The negative values of $\Delta \mathrm{S}$ refer to the stability of the adsorption complex formed.

It remains now to point out that trials has been made to relate the adsorption capacities of the ACs for oxamyl to their textural parameters of the ACs listed in Table 1, one can simply exclude the total surface area $\mathrm{S}_{\mathrm{BET}}$ for example, $\mathrm{q}_{\mathrm{m}}$ of CS65 is about 2.6 time larger than that of CS17 although both exhibit comparable $\mathrm{S}_{\mathrm{BET}}$ values. The total pore volume $\mathrm{V}_{\mathrm{T}}$ may be also excluded for example, $\mathrm{q}_{\mathrm{m}}$ measured value is smaller than that of CS32 although exhibiting higher $\mathrm{V}_{\mathrm{T}}$ than that of CS32. The successful trial was found when was related to the surface area located in non-micropores $S^{\alpha}{ }_{n}$. Fig. 10 depicts $q_{m}$ versus $S^{\alpha}{ }_{n}$. Evidently, a straight line represented the relationship between $\mathrm{q}_{\mathrm{m}}$ and $\mathrm{S}^{\alpha}{ }_{\mathrm{n}}$. Moreover, this straight line passes through the origin which indicates that the surface located in non-micropores is the prominent factor in determining oxamyl adsorption. Oxamyl is a relatively bulky molecule inaccessible to adsorption in micropores. However, within the mesoporous range, i.e. for pores with $r_{m}>1.0 \mathrm{~nm}$, oxamyl adsorption proved to be independent on the value of $r_{m}$.

\section{Conclusions}

The textural properties of steam-activated carbons depend on the percentage burn-off. The initial stage of gasification of a carbonization product with steam creates new micropores. Increasing of $\%$ burn-off widens the pore dimensions via pore walls errosion. Kinetic adsorption of oxamyl by ACs proceeded via pseudo-second-order model, the kinetic adsorption data were more applicable to this model compared with pseudo-first-order model. Adsorption capacities (qm values) higher than $15 \mathrm{mg} / \mathrm{g}$ were calculated by applying the conventional Langmuir model to oxamyl adsorption by some activated carbons. The free energy change of oxamyl adsorption by ACs depicted the feasibility of the adsorption process. The small negative $\mathrm{H}_{\mathrm{o}}$ values referred to the spontaneous physical adsorption and the entropy change indicated the stability of the adsorption complex formed. The adsorption capacity of an activated carbon towards oxamyl may be controlled by the surface area located in non-micropores.

\section{Reference}

[1] Balley, G. W.; White, J.L. Residue Rev. 1970, 32, 29.

[2] Mortland, M. M. Adv. Agron. 1970, 22, 75.

[3] Gertsl, Z. Pestic 1984, 15, 9.

[4] Cohen, S. Z.; Greeger, S. M.; Carsel, R. F.; Endield, G. G.. ACS symp. Ser. Am. Chem. Soc. Washington. DC. USA 1984.

[5] Rothschild, R. E.; Manser, R. J.; Anderson, M. P. Ground Water 1982, 20, 437.

[6] Bansal, O. P.; Gupta, V. J. Indian Soil Sci 1998, 46, 36.

[7] Alaya, M. N.; Hourieh, M. R.; Youssef, A. M.; ELSejarieh, F. Adsorp. Sci. Technol. 2000, 18, 27.

[8] El- Nabarawy, Th.; El- Hakam, S. A.; Youssef, A. M. Adsorp. Sci. Techol. 1996, 13, 509.

[9] Khalil, L. B. Adsorp. Sci. Technol. 1996, 13, 317.

[10] Li, D.; Scala, A. A; Ma, Y. H. Adsorption 1996, $2,227$.

[11] Marshall, W. E.; Johns, M. M. J. Chem. Technol. Biotechnol. 1996, 66, 192.

[12] Youssef, A. M.; El- Khouly, A. I.; Ahmed, A. I; ELShafey, E. I. adsorp. Sci. Technol. 1995, 12, 211.

[13] Youssef, A. M.; Abdl-Bary, E. M.; Samra, S. E; Dawidar, A. M. J. Polym. Sci. 1994, 55, 97.

[14] McKay, G.; El- Geundi, M.; Nassar, M.M. Adsorp. Sci. Technol. 1997, 15, 737.

[15] Gaikar, V. G.; Mandal, T. K.; Kulkarni, R. G. Sep. Sci. Technol. 1996, 31, 259.

[16] Hasany, S. M.; Ahmad, R. Main Group Met. Chem 2003, $26,87$.

[17] McKay, G.; Vong, B.; Porter, J.F. Adsorp. Sci. Technol. 1998, 16, 51.

[18] Weber, Jr. W. G; "Adsorption Technology", Slejke, FL., Ed, Marcel Dekker, New York/ Basel, M.N. 1985, 399.

[19] Alaya, M. N., Youssef, A. M.; Karman, M.; Abdel-AL, H.E. Carbon Science. 2006, 7, 9.

[20] Strelko, V. Jr.; Malik, D. J. J. Colloid Interface Sci. 2000 , 250, 213.

[21] Youssef, A. M.; Ahmed, A. I. 15th Biennial conference on carbon, Philadelphia USA 1981, p. 253.

[22] Rodriguez-Reinaso, F.; Rodriguez-Rames, I., GuerreroRuiz, A.; Lopez- Gonzalaz, D. Appl. Catal. 1986, 21, 257.

[23] Strelko, Vladimir, Jr.; Malik Danish, J. J. Coll. and Interf. Sci. $2000,213$.

[24] Hourieh, M. A.; Alaya, M. N., Youssef, A.M.; El-Sejarieh, F. Adsorp. Sci. Technol. 1999, 17, 675.

[25] Youssef, A. M., Radwan, N. R. E.; Abdel-Gawad, I.; Singer, G. A. A. Colloids and Surfaces. 2005, 252, 143.

[26] Singhal, J. P.; Khan, S. U.; Bansal, O. P. J. Agric. Food. Chem. 1977, 25, 377. 
[27] Brunauer, S. Deming, L. S.; Deming, W. S.; Teller, E., J.Am. Chem. Soc. 1940, 62, 1723.

[28] Brunauer, S.; Emmett, P. H.; Teller, E., J. Am. Chem. Soc. 1938, 60, 309.

[29] Sing, K. S. W. "Surface Area Determination, Proc. Int. Symp., 1970, Bristol, Butterworths, London, UK, P .25.

[30] Maria Jesus S. P.; Jose M. M. J. Chem. Soc. Faraday Trans. 1991, 87, 1237.

[31] Kannan, N.; Sundaram, M. M. Dyes Pigm. 2001, 51, 25.

[32] Ho, Y. S.; Wase, D. A. J.; Forster, C. F. Environ Techol.
1996, 17,71 .

[33] Weber, Jr. W. J; Morris, Jr., J. C. J. Saint Eng. Div., Am. Soc., Civil. Eng. 1963, 89, 31.

[34] Khattri, S. D.; Singh, M. K. Adsorp. Sci. Technol. 1999, 17, 269.

[35] Giles, C. H.; MacEwan, T. H., Proc. $2^{\text {nd }}$ Congr. Surface Activity, London 1959, 457.

[36] Panday, K. K.; Prasod, G.; Singth, U. N., Water Res. 1959, 19,869 . 